\title{
KONSEP MURAH HATI BERDASARKAN LUKAS 6:36
}

\author{
Marlon Taung \\ Sekolah Tinggi Teologi Soteria Purwokerto \\ marlontaung98@gmail.com
}

\begin{abstract}
This paper discusses the meaning of generosity in Luke 6:36. The method used is library research, with the primary sources being the Bible, books, literature, and other sources related to the subject matter. The results showed that the meaning of generosity in Luke 6:36 is to love and forgive fellow human beings. Generosity is a command of God. All believers must practice God's order in concrete actions. Generosity also reflects the Father or is a God-like attribute. Therefore, living generous means expressing the presence of God during life with others.
\end{abstract}

Keywords: Generosity, Mercy, Luke 6:36, God's Command

\begin{abstract}
Abstrak. Tulisan ini membahas makna murah hati dalam Lukas 6:36. Metode yang digunakan adalah penelitian pustaka dengan sumber utama Alkitab, buku, literatur dan sumber lainnya yang berhubungan dengan pokok pembahasan. Hasil penelitian menunjukkan bahwa makna murah hati dalam Lukas 6:36 adalah mengasihi dan mengampuni sesama manusia. Murah hati merupakan perintah Tuhan yang harus dinyatakan dalam tindakan konkrit. Murah hati juga mencerminkan Bapa atau merupakan sifat seperti Allah. Sebab itu hidup bermurah hati berarti menyatakan kehadiran Allah di tengah-tengah kehidupan bersama sesama.
\end{abstract}

Kata kunci: Belas kasihan, perkataan Yesus, Lukas 6:36.

\section{PENDAHULUAN}

Murah hati merupakan kata yang umum di kalangan orang Kristen. Sayangnya praktek praktek kebanyakan orang Kristen kurang mencerminkan kemurahan hati seperti yang diajarkan oleh Kristus. Di tengah pandemi covid-19 saat ini kemurahan hati satu sama lain semakin terkikis karena interaksi sosial dibatasi. 
Menurut Stefan Leks, murah hati adalah suatu sifat yang dimiliki oleh seseorang, di mana dirinya selalu merasa kasihan terhadap orang lain serta ingin menghibur mereka (Leks 2003). Sehingga belas kasihan merupakan partisipasi terhadap orang lain agar terlibat dalam mengambil tindakan untuk ikut serta dalam kesedihan seseorang. Dalam pandangan ini belas kasihan tidak hanya sekadar sebuah rasa kasihan tetapi ada tindakan untuk menolong dan membantu seseorang yang membutuhkan pertolongan. J. J de Heer menyatakan bahwa murah hati atau berbelas kasihan sama dengan perbuatan belas kasih terhadap sesama (Heer 2011).

Ini merupakan kewajiban setiap pengikut Kristus untuk mengerjakan belas kasihan dalam tindakan nyata karena merupakan perintah Tuhan. Seorang Bapa Gereja, Tertullian, mengatakan belas kasihan adalah "Jadilah penyayang, seperti juga Bapamu yang mengasihani kamu" (Tertullian of Carthage 220M) Bermurah hati berarti sama dengan penyayang yang selalu mengambil sebuah tindakan nyata untuk membantu orang yang sedang mengalami kesulitan.

Clement dari Roma menulis "Kasihilah supaya kamu memperoleh kemurahan dari Allah, supaya diampuni” (Clement of Rome 99M). Pernyataan ini tersirat di dalam konsep murah hati menurut Injil Lukas 6:36 yaitu orang yang murah hari akan memperoleh kemurahan dari Allah yaitu pengampunan sehingga jiwanya tidak binasa melainkan memperoleh hidup yang kekal.

Dalam Lukas 6:36 disebutkan bahwa orang yang bermurah hati juga adalah orang yang memberikan pengampunan. Pengikut Kristus wajib melakukan 
BONAFIDE: Jurnal Teologi dan Pendidikan Kristen

www.jurnal.sttissiau.ac.id/Volume 2/Nomor 2/Desember 2021/hal.253-265

perintah Tuhan Yesus untuk mengampuni sesama karena Bapa juga sudah mengampuni dosa kita melalui anak-Nya Yesus Kristus sehingga sebagai anakanak Allah wajib meniru sifat Allah.

Oleh sebab itu, pengikut Kristus dalam mengasihi serta mengampuni, memiliki kesadaran bahwa dirinya sangat membutuhkan anugerah atau kemurahan dari Allah sehingga mau bermurah hati kepada sesama. Pengikut Kristus tidak bisa melupakan kemurahan Allah yang begitu besar kepada dirinya sebagai manusia yang berdosa yang telah mendapat kemurahan Allah dengan cuma-cuma. Apabila mereka menyadari hal itu maka mereka makin bersedia memberikan pertolongan dan mengampuni kesalahan sesamanya.

Polycarpus dari Smyrna berpendapat bahwa berbelas kasihan kepada sesama tujuannya agar memperoleh belas kasihan (Polycarp of Smyrna 155M). Sedangkan Clement dari Alexandria menafsirkan bahwa pengikut Kristus harus berbelas kasih seperti Bapa Surgawi yang maha kasih (Clement Of Alexandria 215M). Sekilas tampaknya pandangan keduanya berbeda tetapi sebenarnya sejalan. Allah adalah yang mengaruniakan kemurahan hati kepada orang yang melakukannya dan Allah juga yang memberikan hidup yang kekal kepada orang yang murah hati kepada sesama. Hal tersebut tercermin dari ucapan Tuhan Yesus sendiri dalam matius 5:7, ketika berkhotbah di atas bukit. Ia mengatakan bahwa orang yang menunjukkan kemurahan akan memperoleh kemurahan dari Allah.

Donald C. Stamps mengemukakan bahwa orang yang murah hati sungguh ingin mengurangi penderitaan orang lain dengan menuntun mereka kepada Kristus 
BONAFIDE: Jurnal Teologi dan Pendidikan Kristen

www.jurnal.sttissiau.ac.id/Volume 2/Nomor 2/Desember 2021/hal.253-265

agar dapat menerima kasih karunia dan pertolongan Allah (Stamps 1999). Dengan demikian, orang yang bermurah hati akan membantu seseorang yang tidak berdaya agar lewat tindakannya, orang itu bisa merasakan pertolongan serta Kasih Tuhan. Seperti perbuatan dalam perumpamaan orang Samaria yang baik hati (Lukas 10:30-37). Orang Samaria tersebut tidak dikalahkan oleh batasan-batasan sosial keagamaan untuk menolong dan berkorban bagi orang yang sedang membutuhkan (Ferguson 1977).

Matthew Henry melihat Lukas 6:36 berbicara tentang aspek kebaikan Allah adalah belas kasihan-Nya, yaitu kebaikan Allah yang ditunjukkan bagi mereka yang berada dalam beban berat. Dalam kemurahan-Nya, Allah menyatakan diri-Nya sebagai Pribadi yang murah hati, yang merasa kasihan kepada mereka yang berada dalam penderitaan. Ia murah hati yang tanpa batas, baik bagi mereka yang benar, maupun bagi mereka yang tidak benar. Ia mengasihi mereka yang memberikan kegembiraan kepada-Nya, tetapi Ia juga tetap mengasihi mereka yang menyusahkan hati-Nya. Allah mengasihi umat-Nya tanpa memandang siapa dan latar belakang seseorang tersebut. Bahkan Ia melimpahkan pemeliharaan-Nya bahkan kepada orang yang paling jahat sekalipun (Henry 2009). Sebab itu seperti dikatakan Ferguson, murah hati mencakup kebaikan, tetapi lebih daripada sekadar kebaikan seorang teman pada waktu susah (Ferguson 1977).

Dari paparan di atas nampak bahwa ada berbagai tafsiran tentang konsep dalam Lukas 6:36 yang berbunyi "Hendaklah kamu murah hati, sama seperti 
BONAFIDE: Jurnal Teologi dan Pendidikan Kristen

www.jurnal.sttissiau.ac.id/Volume 2/Nomor 2/Desember 2021/hal.253-265

Bapamu adalah murah hati”. Penelitian ini bertujuan mengetahui apa sesungguhnya makna murah hati melalui suatu studi pustaka.

\section{METODE PENELITIAN}

Metode yang digunakan oleh penulis dalam penelitian ini adalah penelitian pustaka. Nazir mendefinisikan studi kepustakaan sebagai teknik pengumpulan data dengan melakukan penelaahan terhadap buku, literatur, catatan, serta berbagai laporan yang berkaitan dengan masalah yang ingin dipecahkan (Nazir 2007). Penulis menggunakan berbagai literatur yang telah membahas mengenai konsep murah hati dalam Lukas 6:36.

\section{HASIL PENELITIAN}

Komunitas Lukas adalah jemaat kota Roma atau jemaat di pinggiran kota Roma yang sedang menghadapi pergumulan. Pada tahun-tahun penulisan Injil Lukas, pada akhir abad pertama (sekitar tahun 80-90) Kaisar Domitianus adalah penguasa Romawi yang memerintah sekitar 15 tahun lamanya (antara tahun 8196) (Ludwig 1997).

Dalam masa pemerintahannya orang-orang Kristen berada dalam posisi terhimpit di bawah tekanan bahkan penindasan dari penguasa. Bagi seluruh warga kekaisaran Romawi termasuk orang-orang Kristen di dalamnya, Domitianus mengharuskan mereka untuk menyembah dia sebagai tuhan. Dia menyebut dirinya sendiri sebagai Dominus et Deus"' (Tuhan dan Allah). Memang mereka dapat saja menghormati penguasa dan berdoa baginya namun mereka tidak dapat 
BONAFIDE: Jurnal Teologi dan Pendidikan Kristen

www.jurnal.sttissiau.ac.id/Volume 2/Nomor 2/Desember 2021/hal.253-265

membakar dupa bagi patungnya atau tidak ikut serta dalam memberikan kurban (Stambaugh dan Balch 1994).

Pilihan-pilihan yang demikian membawa orang-orang Kristen dilematis, sebab di satu pihak mereka mencoba taat kepada pemerintah tetapi di lain pihak mereka di perhadapkan pada pilihan untuk percaya kepada Allah. Domitianus tidak memiliki toleransi terhadap agama lain. Barangsiapa bahkan dibakar yang menolak pemujaan terhadap kaisar, di tuduh sebagai seorang yang "' atheis". Mereka dianggap sebagai penyebab kekacauan dalam pemerintahan maupun dalam masyarakat, akibatnya mereka dianiaya, dibunuh, dibantai bahkan dibakar hidup-hidup. Selain tantangan diatas, ada juga persoalan yang membuat sehingga banyak para pengikut Kristus ditindas dan dianiaya, kekristenan lahir di kalangan orang Yahudi dan pada mulannya orang-orang Romawi menganggap orang-orang Kristen sebagai sekte (aliran) kaum Yahudi (Stambaugh dan Balch 1994).

Tujuan kitab Lukas adalah memberitakan kabar baik bagi semua orang, khususnya orang miskin, buta, tertindas, hingga orang-orang berdosa bahwa pembebasan sudah dekat. Melalui kedatangan Yesus, mereka akan berbahagia karena Yesus membuka suatu harapan masa depan yang baru. Lukas memberi penekanan bahwa Yesus adalah sahabat untuk orang-orang yang rendah. Lukas berupaya mendorong komunitasnya supaya memiliki peneguhan iman agar dapat melakukan pengajaran-pengajaran yang Yesus berikan. Bahkan di tengah-tengah pergumulan jemaatnya, Lukas menasihatkan supaya mereka tetap menunjukkan identitas dan karakter mereka sebagai orang-orang Kristen atau pengikut Yesus. 
BONAFIDE: Jurnal Teologi dan Pendidikan Kristen

www.jurnal.sttissiau.ac.id/Volume 2/Nomor 2/Desember 2021/hal.253-265

\section{PEMBAHASAN}

Murah hati bahasa aslinya adalah Elee yang berarti Mercy belas kasihan yang merupakan tindakan yang konkrit. Murah hati berarti suka memberi, tidak pelit dan suka menolong. Berbelas kasihan bukan hanya sekadar menolong atau mengasihi sesama tetapi memberikan pengampunan kepada seseorang yang bersalah. Bermurah hati merupakan perintah Tuhan Yesus kepada para murid-Nya yang harus dikerjakan supaya orang lain dapat melihat dan merasakan kasih Allah dan kasih Kristus di dalam tindakan para pengikut Kristus.

\section{Murah Hati Dalam Mengasihi}

Bermurah hati kepada sesama berarti mengasihi sesamanya. Kasih adalah murah hati. Dalam 1 Korintus 13:4. Orang yang mengasihi sesamanya adalah orang yang memiliki kemurahan hati. Seperti yang di gambarkan dalam Lukas 10:25-37 tentang orang samaria yang baik hati. Orang samaria memberikan pertolongan kepada sesamanya yang sedang terluka. Itulah kemurahan hati yang dimaksudkan dalam Lukas 6:36.

Hidup bermurah hati dengan mengasihi sesama akan menjadi teladan bagi orang-orang disekitarnya apalagi orang-orang yang belum mengenal Tuhan. Mengasihi bukan dengan motivasi supaya dihargai oleh orang lain ( Matius 6:1), tetapi menaati-Nya perintah Tuhan karena benar-benar mengasihi Allah dan Umat-Nya (Wiersbe 2000). Mengasihi sesama bukan hanya sekadar perkataan tetapi dalam perbuatan (Hendi 2019). Bermurah hati bagi para pengikut Kristus 
BONAFIDE: Jurnal Teologi dan Pendidikan Kristen

www.jurnal.sttissiau.ac.id/Volume 2/Nomor 2/Desember 2021/hal.253-265

bukan sekadar perbuatan baik tetapi perbuatan baik dalam kebenaran (1 Yoh. 3:18). Setiap orang percaya harus mengenal bahwa Allah adalah murah hati.

\section{Murah Hati Dalam Mengampuni}

Menurut Ferguson, kemurahan hati memiliki dua sikap yang berbeda yaitu dalam mengasihi dan mengampuni. Tidak hanya mengasihi orang yang kita lihat kesakitan, menderita, sengsara, atau berdukacita tetapi juga harus mengampuni orang-orang yang berbuat salah (Ferguson 1977).

Harrington menyatakan bahwa setiap murid Yesus dituntut untuk memiliki sikap murah hati yang selalu bersedia mengampuni tanpa batas. Jumlah pengampunan yang dikatakan oleh Yesus "tujuh puluh kali tujuh kali". Artinya orang Kristen tidak mempunyai hak untuk menentukan batas untuk mengampuni (Harrington 2002). Allah yang digambarkan dalam Alkitab adalah Allah yang murah hati yang suka mengampuni. Allah itu murah hati sehingga di dalam kemurahan-Nya, Ia mengampuni dosa manusia. Sebab itu setiap orang yang telah menerima pengampunan dituntut untuk memberikan pengampunan kepada sesama.

Apabila seseorang tidak bersedia mengampuni sesamannya, padahal ia telah menerima pengampunan, maka ia akan menerima hukuman. Dalam Matius 18:20-35 digambarkan perumpamaan tentang hamba yang tidak menunjukkan belas kasihan padahal Ia sendiri sudah mendapat belas kasihan. Oleh sebab itu, para pengikut Kristus apabila tidak bermurah hati dalam memberikan pengampunan maka akan menerima hukuman. 
Menurut Martin Harun, akan ada hukuman di akhir zaman apabila para murid Yesus tidak mengampuni saudaranya. Pada pengadilan terakhir, Tuhan tidak akan mengampuni orang yang hanya menerima pengampunan tetapi tidak rela meneruskan kepada sesama yang bersalah terhadapnya (Harun 2017).

\section{Bapa adalah Murah Hati}

Anak-anak Allah dituntut bermurah hati karena Bapa adalah murah hati. Tuhan Yesus memberikan perintah untuk bermurah hati sebab dengan bermurah hati membuat karakter mereka sama dengan Bapa di sorga. Bukti nyata bahwa Bapa itu maha pemurah adalah Ia rela memberikan putera-Nya Yesus Kristus untuk mati di kayu salib demi menebus dosa umat manusia, oleh-Nya kita diselamatkan.

Selama pelayanan-Nya di bumi, Tuhan Yesus juga selalu menunjukkan kasih dan kemurahan hati terhadap semua orang. maka dari itu, 'Barangsiapa mengatakan, bahwa ia ada di dalam dia, ia wajib hidup sama seperti Kristus telah hidup.' (1 Yoh. 2:6). Dalam Perjanjian Lama, Allah disebut sebagai Allah yang murah hati atau penuh dengan belas kasihan, Kel. 34:6; Ul. 4:31; Mzm. 78:38; 86:15. Kita diselamatkan bukan karena kita layak atau karena perbuatan baik kita, melainkan oleh karena kasih karunia dan kemurahan Allah.

Di dalam Injil Lukas 6:36 menyatakan bahwa Bapa adalah murah hati. Keyakinan bahwa Allah adalah murah hati yang pengasih merupakan keyakinan yang mendasari semua bagian Perjanjian Baru. Allah memerintahkan manusia untuk mengasihi Allah karena Allah lebih dahulu mengasihi manusia, dengan 
BONAFIDE: Jurnal Teologi dan Pendidikan Kristen

www.jurnal.sttissiau.ac.id/Volume 2/Nomor 2/Desember 2021/hal.253-265

mengutus anak-Nya yang tunggal, supaya kita hidup oleh-Nya (1 Yohanes 4:910). Dalam tulisan-tulisan Yohanes, kasih Allah kepada anak-Nya merupakan bukti utama bahwa murah hati adalah sifat Allah yang hakiki (Yohanes 3:35;5:20; 10:17;15:9; 16:27;17:23-24) (Guthrie 2011). Kedatangan Kristus ke dalam dunia merupakan puncak kasih Allah kepada manusia (Yohanes 3:16).

William Barclay menyatakan ada lima penjelasan tentang Allah adalah murah hati yaitu: (1) Ia adalah penjelasan mengenai penciptaan; (2) Ia adalah penjelasan mengenai kehendak bebas; (3) Ia adalah penjelasan mengenai pemeliharaan; (4) Ia adalah penjelasan mengenai penebusan; dan (5) Ia adalah penjelasan mengenai kehidupan di seberang. Allah adalah murah hati memiliki makna lebih dari sekadar Allah pengasih, tetapi ini menyatakan bahwa murah hati adalah sifat Allah yang hakiki (Barclay 2006).

Allah menyatakan murah hati ini melalui pemberian anak-Nya, yang diutus sebagai manusia untuk menjadi penebus, supaya setiap orang yang percaya kepada-Nya, tidak binasa, melainkan kehidupan yang kekal Yohanes 3:16; 8:42. Itulah kemurahan Allah yang ditunjukkan kepada manusia. Berarti dapat disimpukan bahwa, Bapa adalah Bapa yang murah hati. Kristus juga adalah murah hati. Kemurahan hati Tuhan Yesus dapat dilihat ketika St. Petrus menyangkal Yesus tiga kali, tetapi Tuhan Yesus telah menatapnya dengan penuh belas belas kasihan (Luk 22:61). Itulah kemurahan hati Tuhan Yesus, oleh karena kemurahan Tuhan Yesus, Tuhan Yesus mengampuninya tujuh puluh tujuh kali dan tidak mengingatnya lagi (Scanlon 2011). 
Bapa adalah murah hati, dengan kemurahan hati Allah, Ia memberikan penyelamat bagi kita sebagai anak-anak-Nya (1 Petrus 1:3). Bapa adalah murah hati atau penuh dengan belas kasihan, sehingga dengan kemurahan Allah atau kasih setia Allah, Ia memberikan jalan keselamatan kepada manusia yang sudah berdosa. Seperti yang dikatakan dalam Roma 5:10 oleh kematian Yesus Kristus, hubungan kita di perdamaikan dengan Allah. Tujuan Allah memberikan keselamatan kepada kita sebagai anak-anaknya, lewat kematian Kristus dengan tujuan mendamaikan hubungan kita dengan Allah. Sebab hubungan manusia dengan Allah putus karena melakukan dosa.

\section{Hasil Dari Murah Hati}

Orang yang bermurah hati kepada sesama akan menjadi serupa dengan Allah atau menjadi sama seperti Allah. Seperti yang dikatakan oleh Tuhan Yesus

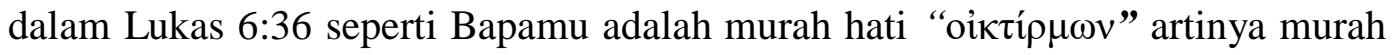
hati. Bermurah hati dapat membawa kita menjadi serupa dengan Allah. Bagi para pengikut Kristus, ketika melakukan murah hati kepada sesama dalam mengasihi dan memberikan pengampunan kepada seseorang, dapat membawa karakter kita menjadi semakin serupa dengan dengan Allah dalam Kristus. Menjadi orang murah hati, seperti Kristus murah hati, seperti Dia yang sempurna (Henry 2009).

Murah hati kepada sesama itu mencerminkan sifat Allah yang murah hati yang mengasihi dan memberikan pengampunan. Seperti yang dikatakan oleh Tuhan Yesus "Hendaklah kamu murah hati, sama seperti Bapamu adalah murah hati." (Lukas 6:36). Frasa "Seperti Bapa mu yang adalah murah hati" artinya 
BONAFIDE: Jurnal Teologi dan Pendidikan Kristen

www.jurnal.sttissiau.ac.id/Volume 2/Nomor 2/Desember 2021/hal.253-265

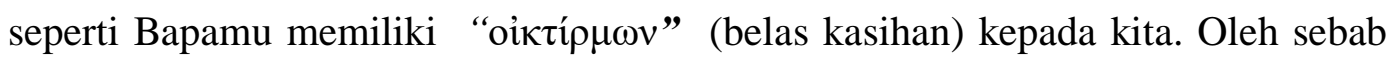
itu, perintah Tuhan Yesus untuk berbelas kasihan itu sangat penting untuk dikerjakan karena dengan berbelas kasihan orang lain dapat merasakan dan melihat kasih Kristus di dalam diri orang percaya.

\section{Murah Hati Akan Dikasihi Allah}

Mengerjakan kemurahan hati kepada orang lain akan menjadikan anakanak Allah serupa dengan Allah. Selain itu mereka juga akan memperoleh kemurahan dari Allah sehingga jiwanya diselamatkan pada saat penghakiman. Jadi dapat disimpulkan bahwa kemurahan Allah hanya tersedia bagi orang-orang yang melakukan perintah Tuhan untuk bermurah hati kepada sesama. Hal ini akan membawa anak-anak Allah pada keselamatan atau memperoleh hidup yang kekal. Berbelas Kasihan yang penulis maksudkan adalah belas kasihan yang dilandasi dengan tindakan nyata.

\section{KESIMPULAN}

Murah hati dalam Lukas 6:36 memiliki dua makna yaitu mengasihi sesama dan mengampuni sesama. Ini merupakan standar hidup orang percaya yang mencerminkan sifat Bapa dan Kristus. Orang Kristen atau para pengikut Kristus harus bermurah hati karena Allah dan Tuhan Yesus sudah bermurah hati kepada mereka. Selain itu, dengan hidup bermurah hati orang percaya akan memperoleh kemurahan dari Allah sendiri, supaya akan empunya Kerajaan Sorga. 
BONAFIDE: Jurnal Teologi dan Pendidikan Kristen

www.jurnal.sttissiau.ac.id/Volume 2/Nomor 2/Desember 2021/hal.253-265

\section{DAFTAR PUSTAKA}

Barclay, William. 2006. Pemahaman Alkitab Setiap Hari Surat-Surat Yohanes dan Yudas. Jakarta: BPK Gunung Mulia.

Clement Of Alexandria. 215M. "Luke 6:36." Catena Bible \& Commentaries. 215M. http://catenabible.com/com/5735e12fec4bd7c9723bbcb2.

Clement of Rome. 99M. "Luke 6:36." Catena Bible \& Commentaries. 99M. https://catenabible.com/com/5735e130ec4bd7c9723bbcb7.

Ferguson, Sinclair B. 1977. Khotbah di Bukit: Cermin Kehidupan Sorgawi di Tengah Dunia Berdosa. Surabaya: Momentum.

Guthrie, Donald. 2011. Teologi Perjanjian Baru I. Jakarta: BPK Gunung Mulia.

Harrington, Daniel J. 2002. Tafsir Injil Matius, Dalam Tafsir Alkitab Perjanjian Baru. Yogyakarta: Kanisius.

Harun, Martin. 2017. Matius: Injil Segala Bangsa. Yogyakarta: Kanisius.

Heer, J.J. de. 2011. Tafsiran Alkitab Injil. Jakarta: Gunung Mulia.

Hendi, H. 2019. Inspirasi Kalbu 3. Yogyakarta: Leutikaprio.

Henry, Matthew. 2009. Tafsiran Matthew Henry: Injil Lukas 1-12. Surabaya: Momentum.

Leks, Stefan. 2003. Tafsir Injil Lukas. Yogyakarta: Kanisius.

Ludwig, Charles. 1997. Para Penguasa Pada Zaman Perjanjian Baru. Bandung: Kalam Hidup.

Nazir, Mohammad. 2007. Metode Penelitian. Jakarta: Ghalia Indonesia.

Polycarp of Smyrna. 155M. "Luke 6:36." Catena Bible \& Commentaries. 155M. http://catenabible.com/com/5735e12fec4bd7c9723bbcb0.

Scanlon, Paul. 2011. "The Difficulty of Forgiving Ourselves." Spiritual Life 57 (1): 42-47.

Stambaugh, John, dan David Balch. 1994. Dunia Sosial Kekristenan Mula-mula. Jakarta: BPK Gunung Mulia.

Stamps, Donald C. 1999. Alkitab Penuntun Hidup Berkelimpahan. Malang: Gandum Mas.

Tertullian of Carthage. 220M. "Luke 6:36." Catena Bible \& Commentaries. $220 \mathrm{M}$.

Wiersbe, Warren W. 2000. Setia di dalam Kristus: Tafsiran I dan II Timotius, dan Titus. Bandung: Kalam Hidup. 